\title{
LINGUISTICS
}

DOI:

\section{WINGED WORDS IN SCHOOL: MINIMUM AND MAXIMUM}

\author{
Valerij Mokienko \\ Doctor of Philological Sciences, Professor, \\ St. Petersburg State University \\ (St. Petersburg, Russia) \\ e-mail: mokienko40@mail.ru
}

\begin{abstract}
The purpose of the article is to show the role of winged words and expressions as language repositories of cultural heritage and the possibility of teaching them at school and university. The material of Russian winged words demonstrates the correlation of knowledge of winged words with the educational level of native speakers. For this purpose, the author has applied the method of interviewing students of Russian universities. The survey data of students on this issue are presented and analyzed. On this basis, an approximate minimum of such linguistic units, necessary for mastering the obligatory knowledge of Russian literature, is outlined. The minimum is determined on the basis of maximum of the winged words and expressions described in large dictionaries, which may reflect a deeper knowledge of the students. The materials of published dictionaries of winged words and expressions can significantly expand such knowledge and with the necessary accuracy to determine the quantitative and qualitative reflection of literary sources in the „winged“ heritage of the Russian language. As a result of the proposed research, a reference dictionary of Russian winged words and phrases will be prepared for students of schools and universities in Russia and abroad.
\end{abstract}

Key words: lexicography, phraseology, phraseography, catchwords and expressions, catchwords dictionaries

\section{КРЫЛАТЫЕ СЛОВА В ШКОЛЕ: МИНИМУМ И МАКСИМУМ*}

\author{
Валерий Михайлович Мокиенко \\ Доктор филологических наук, профессор, \\ Санкт-Петербургский государственный университет \\ (Санкт-Петербург, Россия) \\ e-mail: mokienko40@mail.ru
}

\begin{abstract}
Аннотация. Цель статьи - показать роль крылатых слов и выражений как языковых хранилищ культурного наследия и возможности их преподавания в школе и вузе. На материале русских крылатых слов демонстрируется соотношение знаний крылатики с образовательным уровнем носителей языка. С этой целью автором применена методика опроса студентов вузов России. Приводятся и анализируются данные анкетирования студентов по этой проблематике. На этой основе очерчивается примерный минимум таких языковых единиц, необходимый для усвоения обязательных знаний русской литературы. Минимум определяется на основе максимума крылатых слов и выражений, описанных в больших словарях, которые могут отражать более глубокие познания обучаемых. Материалы изданных словарей крылатых слов и выражений позволяют значительно расширить такие познания и с необходимой точностью определить количественное и качественное отражение литературных источников в «крылатом» наследии русского языка. В результате предлагаемого исследования будет подготовлен словарь-справочник русских крылатых слов и выражений для учащихся школ и вузов России и зарубежья.
\end{abstract}

Ключевые слова: лексикография, фразеология, фразеография, крылатые слова и выражения, словари крылатых слов

ВВЕДЕНИЕ. Дискуссии об усовершенствовании системы образования в современной России и Европе так или иначе приводят к констатации, что молодёжь, «приговорённая» к Интернету и молниеносному получению любой информации по мобильным контактам, теряет вкус к чтению классической литературы. Исследования показывают, что такая констатация объективна. Так, анкетирование студентов России, Германии и Словакии обнаружило заметные лакуны в знании библейских крылатых выражений (Baláková 2013). Аналогичны результаты анкетирования, предпринятого участниками проекта «Классики русской литературы в зеркале крылатых выражений (словари-справочники)», поддержанного РФФИ - Е.И. Зыковой, О.В. Ломакиной, В.М. Мокиенко (руководитель проекта) и Н.А. Росовой. Ответы анкетируемых из вузов Москвы, Петербурга, Пскова, Нижнего Новгорода, Тулы, Магнитогорска и других городов Российской Федерации обнаружили большие пробелы в литературных познаниях. При этом программы школьного и вузовского обучения включают не только необходимый минимум таких познаний, но и предлагают достаточно широкий диапазон авторов, которые должны изучаться. Но в реальности программы остаются либо полностью невыполненными, либо чрезвычайно «усечёнными» из-за известных формальных мер «оптимизации» обучения.

\footnotetext{
* Исследование выполнено при финансовой поддержке РФФИ в рамках научного проекта № 17-29-09064 «Классики русской литературы в зеркале крылатых выражений», реализуемого в Санкт-Петербургском государственном университете.
} 
Преподаватели русского языка и литературы различными способами стремятся восполнить образовавшуюся лакуну и повысить интерес обучаемых к творчеству писателей и поэтов. Одним из методических приёмов, способствующих этому, может стать, как кажется, работа с так называемыми крылатыли словами и выражениями. Под этим термином традиционно понимаются образно-экспрессивные лексические, фразеологические и афористические единицы разного типа, вошедшие в язык из определённого литературного, исторического, культурологического источника: меткие словечки или изречения, произнесенные тем или иным историческим лицом при определенных обстоятельствах; цитаты из произведений художественной литературы, публицистики, кинофильмов; «рекламные ролики» и т.п. Таковы, например: Иуда (Библия), Ахиллес (античная мифология), Скалозуб (А.С. Грибоедов); $A$ Васька слушает, да ест (И.А. Крылов); И дым отечества нам сладок и приятен (А.С. Грибоедов); Я памятник себе воздвиг нерукотворный (А.С. Пушкин); Богатые тоже плачут (название мексиканского телесериала); сладкая парочка (телереклама «Твикса»). Основной трудностью употребления крылатых слов и выражений является неточное или ошибочное знание их первоисточника, а также неверное воспроизведение их формы и содержания. Причём такие трудности отражаются не только в потоке разговорной речи и Интернета, но и в разных формах обучения, официального общения и собственного творчества пишущих и говорящих.

Образный оборот крылатое слово восходит к Гомеру, но в качестве филологического термина он вошёл в обиход благодаря сборнику «Крылатые слова» („Geflügelte Worte“), изданному в 1864 г. немецким филологом Г. Бюхманом. Принятое традиционное определение термина крылатые слова предполагает, что их основным категориальным признаком является «авторство» меткого слова и изречения, возможность причислить их к конкретному историческому лицу.

В этом - основная специфика и основная трудность современного литературного употребления крылатых слов и выражений. Многие пишущие и говорящие не могут точно идентифицировать источник таких единиц, а неточное указание на авторство разрушает или искажает историческую и культурологическую информацию, которая аккумулирована в них. Вторым распространенным типом ошибочного употребления крылатых слов и выражений является искажение их формы и содержания. Ср. характерные примеры из сочинений абитуриентов (Norman 2004, 159-165): Луч света в тёмном коридоре; Это мы, призраки коммунизма, победили всё; У каждого человека есть место для подвига; И несётся навстречу будущему гусь-тройка; Советский Союз назван страной восходящего солниа не случайно; Лучше умереть стоя, чем лёжа; Дон Кихот и его верная лошадь Ренессанс запомнились мне ещё с детских лет; Пусть всегда будет солнце! Эти слова звучат одинаково на всех языках мира! Ромео и Джульетта были очень молодыми и ещё не успели обрасти пережитками прошлого; Родители Ильи Муромиа были простые колхозники; У Тараса Бульбы было два сына: один - Oстап, а второй - Бендер; В природе ничего не исчезает, а заносится в Красную книгу...

Разумеется, не всегда вариантность крылатых слов и выражений является ошибочной: как и любые языковые единицы, они порождают и динамические изменения формы, не отражающиеся на их основном содержании. Так, например, библейское выражение отделять овнов (ц.-слав. овец) от козлищ (ц.-слав. козлов) заменяется сейчас на более современный вариант отделять овец от козлищ, а знаменитое изречение А.П. Чехова $B$ человеке должно быть всё прекрасно: и личо, и одежда, и душа, и мысли употребляется сейчас чаще в сокращенном виде - В человеке должно быть всё прекрасно.

Наконец, довольно часто крылатые слова и выражения становятся объектом языковой игры, порождают каламбуры, столь популярные в современной прессе, «Интернете» и живой речи (Walter, Mokienko 2005). Например: Бить или не бить - вот в чём вопрос (вместо шекспировского Быть или не быть - вот в чём вопрос); Кесарю кесарево, самураю - харакири (вместо библеизма Кесарево кесарю, а Божие Богу); Мой дядя cамых честных грабил... (вместо пушкинского Мой дядя самых честных правил) и т.п.

Разграничение случаев ошибочного употребления крылатых слов и выражений от нарочитого, стилистически оправданного - одна из задач исследования обозначенной проблематики. Дидактическая же цель решения этой проблемы предполагает отбор и рекомендацию таких языковых единиц, которые уже прошли «обкатку» временем и активно функционируют в современном русском языке и речи. Именно поэтому составители проектируемого словаря из максимума описанных прежде крылатых слов и выражений отбирают для словника наиболее частотные и узнаваемые носителями языка единицы.

ОБЗОР ЛИТЕРАТУРЫ. Жанр такого рода словарей, инициированных Г. Бюхманом, сразу же стал популярен и до сих пор остаётся востребованным в России. И. Редников уже в 1883 г. по образцу немецкого собрания издал «Сборник замечательных изречений, цитат, поговорок и т. п. различных времён и народов с историческим и сравнительным объяснением» (Rednikov 1883). В 1891 г. С.В. Максимов издал «Крылатые слова» (Maksimov 1891), хотя при этом значительно расширил этот термин, включив в него и народные пословицы и поговорки. Десять лет спустя М.И. Михельсон издаёт капитальный двухтомный словарь «Русская мысль и речь. Своё и чужое. Опыт русской фразеологии. Сборник образных слов и иносказаний» (Михельсон 1903, 1905), несколько раз переизданный и сейчас (Mihel'son 1994). Словник этого словаря, по сравнению с собранием Г. Бюхмана, значительно расширен за счёт народных пословиц и поговорок, цитат, фраз и т.п., а материал расположен не по источникам, а в сплошном алфавитном порядке.

С.Г. Займовский (Zaymovskiy 1930) и В.3. Овсянников (Ovsyannikov 1933) продолжили традицию словарного описания крылатых слов и выражений, хотя подошли к этой проблеме по-разному - как лексикографически, так и идеологически. Новым словом в крылатологии стал сборник «Крылатые слова. Литературные цитаты. Образные выражения» Н.С. и М.Г. Ашукиных, изданный в 1955 г. и несколько раз 
переиздававшийся (Ashukiny 1955, 1966, 1999). Термин крылатые слова ими понимается в том же узком значении, как у родоначальника этого жанра Г. Бюхмана, обозначая языковые единицы, «источник которых может быть установлен» (Ashukiny 1966, 4).

Современные лингвисты и лексикографы интенсивно исследуют крылатые слова и выражения в русле теории интертекста, прецедентного текста и др. (Mokienko 2003; Lomakina, Mokienko 2019). С конца прошлого века появилось много попыток словарного описания крылатых слов и выражений русского языка, анализ которых дан С.Г. Шулежковой в её докторской диссертации и в монографии «Крылатые выражения русского языка, их источники и развитие» (Shulezhkova 2002), а также в Предисловии «Крылатые слова и выражения русского языка как объект лексикографического описания» ко 2-му изданию нашего «Большого словаря русских крылатых слов и выражений» (Berkov, Mokienko, Shulezhkova 2008, 1, 3-15). Из последних значительных публикаций, кроме переизданного последнего словаря, можно выделить сборники Л.П. Дядечко (2001-2003) и В. Серова (2003). Популярность таких словарей вполне естественна, ибо крылатые слова и выражения КС, по характеристике В.П. Беркова (Berkov, Mokienko, Shulezhkova 2008, 1, 16-30), являются «золотым фондом мировой и национальной культуры». Вот почему изучение их в школе и вузе - необходимая предпосылка для воспитания языкового вкуса и уровня образованности нашей молодёжи.

МЕТОДЫ ИССЛЕДОВАНИЯ. Маркированность источником при этом - это не языковой, а экстралингвистический признак. Вот почему в лингвистическом отношении интертекстемы, большую часть которых составляют именно крылатые слова и выражения, характеризуются исключительной разнородностью и не сводимы в некую целостную уровневую систему. В них нельзя по своей сути искать единую языковую природу. «Это скорее не строгие единицы, как слова, морфемы, предложения, фразеологизмы, а такие элементы, которые относятся, может быть, больше к психологическим феноменам памяти, чем собственно языка как системы, - метко подчеркивает пограничный и лингвистически разнородный характер интертекстем А.Е. Супрун, добавляя при этом: - но поскольку эта память - о словесных явлениях, она примыкает к языковому устройству и интертекстемы могут рассматриваться как часть языка» (Suprun 2001, 106). В этом смысле интертекстемы являются своего рода «дайджестами текстов». Таким образом, отношение интертекстем к языку определяется их воспроизводимостью памятью говорящего, а не их уровневой однородностью.

Экстралингвистический параметр крылатых слов и выражений весьма действенно влияет на их функционирование. Ведь именно маркированность источником создает у носителя языка их восприятие как текста in sich и an sich. Будучи мини-текстом, интертекстема в макси-тексте ведёт себя весьма активно и полифункционально: то как его строевой элемент типа фразеологизма, то как его законченный фрагмент паремиологического типа, то как фрагмент своего прототипа, трансформированный почти до неузнаваемости. Функциональный статус интертекстем вообще чрезвычайно разнороден из-за разнородности их чисто лингвистического статуса. Стремление отождествить интертекстему (resp. крылатое слово или выражение, прецедентный текст, текстовую реминисценцию, логоэпистему, эптологизм и т.п.) с единицей конкретного уровня языковой системы обречено на неудачу, поскольку сам критерий её выделения - критерий экстралингвистический. Поэтому та часть крылатых слов и выражений, которая функционально и структурно соответствует словосочетанию, может быть отнесена к фразеологии. Интертекстемы же с законченной паремиологической структурой могут быть отнесены к пословицам, а крылатые слова-мифологемы или имена собственные, претерпевшие метафоризацию - к коннотативным лексемам. В этом смысле интертекстемы являются генетическим источником самых разных по структуре и семантике языковых единиц, но таковыми их делает лишь «обкатанность» языковой системой, воспроизводимость в готовом виде. Следовательно, методы исследования и лексикографического описания каждой разновидности крылатых слов и выражений должны быть различными, обусловленными их языковой спецификой. Такая специфика накладывает свой отпечаток и на отбор крылатых слов и выражений, рекомендуемых для школьного обучения.

РЕЗУЛЬТАТЫ И ДИСКУССИЯ. Словник анонсируемого Словаря должен включать наиболее употребительные крылатые слова и выражения с точно паспортизированным источником. Как показывает опыт большинства справочников по русским и европейским языковым единицам такого рода, частотность и корректность их употребления непосредственно связана именно с идентификацией их источника. Незнание его приводит не только к формально-смысловым искажениям, но и к смешению исторической и культурологической ретроспективы. Целью школьного и вузовского справочника поэтому является как точная идентификация авторства описываемых крылатых слов и выражений, так и регистрация их исходной формы, которая в большинстве случаев и является нормативной.

Взаимодействие «корректная паспортизация источника» $\Leftrightarrow$ «правильность употребления», разумеется, не всегда столь однозначно и прямолинейно, как этого бы хотелось нормализаторам. Хотя «правильность» употребления во многом действительно определяется исходной корректной формой, одно лишь указание на неё не всегда является самодостаточным для корректной рекомендации нормативного употребления.

Причины этого различны.

Во-первых, в корпусе русских крылатых слов и выражений существует опредёленное число единиц, источник которых приписывается разным авторам, что делает точную историческую и культурологическую его паспортизацию несколько относительной. Так, знаменитая крылатая фраза Чацкого из комедии А.С. Грибоедова «Горе от ума» - И дым отечества нам сладок и приятен восходит к латинской пословице Et fumus patriae dulcis; Dulcis fumus patriae (букв. И дым отечества сладок; Дым отечества сладок). Аналогичные 
изречения встречаются в античной литературе - напр., в «Одиссее» Гомера: «... Видеть хоть дым, от родных берегов вдалеке восходящий...» $(1,56-58)$ или у Овидия («Понтийские послания» $(1,3,33)$ : «... Чтоб мог увидеть дым отечественного очага». В русском языке пословица появляется, видимо, в 70-е гг. XVIII в., когда в России увеличивается интерес к античности. Она приводится в разных вариациях Г.Р. Державиным (стихотворение «Арфа» - 1798), П.А. Вяземским, К. Батюшковым. Крылатой же она, тем не менее, стала в русском литературном языке благодаря употреблению в комедии «Горе от ума» А. С. Грибоедова (д. 1, явл. 7 - 1824), что и акцентируется в предлагаемом словаре.

Во-вторых, поскольку споры о статусе крылатых слов и выражений продолжаются, в их состав часто включаются и единицы с «коллективным» автором. Сюда относятся прежде всего фольклоризмы и мифологизмы, например: сказка про белого бычка, молочные реки, кисельные берега; Пойди туда, не знаю куда, возьми то, не знаю что; пуп земли; лебединая песня; Капля долбит (точит) камень; Ахиллесова пята и т.П. В новейшее время такого рода крылатые слова и выражения пополняются за счёт оборотов (особенно иноязычных словосочетаний) из современной прессы, телепередач, «Интернета», рекламы и т.П., например: мозговая атака, мы все в одной лодке; кошмарить бизнес; прорабы перестройки; Сам себе режиссёр; Реклама - двигатель торговли; сладкая парочка и т.п.

В-третьих, многие крылатые слова и выражения в процессе их усвоения русским литературным языком и разговорной речью начинают варьироваться, отклоняясь от «буквы» первоисточника, но сохраняя его дух. Такие варианты было бы ошибочно считать «неправильными»: они - лишь свидетельство динамики языковой системы, её постоянной эволюции. Так, выражение герой нашего времени известно как название романа М. Ю. Лермонтова (1840). Возможно, однако, что оно навеяно поэту «Рыцарем нашего времени» Н. М. Карамзина. В свою очередь, крылатое выражение калиф на час, связанное с арабской сказкой «Сон наяву, или калиф на час» из сборника «Тысяча и одна ночь» у Н.А. Некрасова превратилось в вариант рыцирь на час и как название его стихотворения (1863) стало популярным. В свою очередь, от этих оборотов образована целая серия речевых или индивидуально-авторских вариантов: герой на час, факир на час, чемпион на час, поэт на час, звезда на час, лидер на час, миллионер на час, банкир на час и т.п. Все они понятны читателю именно потому, что ему известен их фольклорный и литературный прототип.

Наконец, крылатые слова и выражения могут становиться крылатыми в разных формах: либо в форме законченного предложения (в качестве афоризма), либо в форме устойчивого словосочетания (в качестве фразеологизма), либо «сгущаясь» до одного слова. Один и тот же источник в таком случае почти одновременно порождает целую «гроздь» крылатых слов и выражений, которые с позиций правильности речи являются равно «правильными», соответствующими литературной норме. Так, например, пушкинская крылатая фраза $И$ даль свободного романа/ Я сквозь магический кристалл/ Еще не ясно различал употребляется и в полной форме, и в виде словосочетаний даль свободного романа и магический кристалл (Мокиенко, Сидоренко 1999, 234, 162, 332-334).

Близки к этому и языковые единицы, образованные, например, от античных мифологических наименований. Так, крылатое слово Фемида, обозначавшее древнегреческую богиню правосудия, стало переносно символом правосудия и породило несколько крылатых выражений: aлтарь Фемиды, весы Фемиды, жрецы Фемиды, сыны Фемиды, храм Фемидыл.

Все названные случаи «отклонений» крылатых слов и выражений от первоисточника не опровергают необходимости и оправданности ориентации на общий для русской литературной нормы историкоэтимологический (resp. источниковедческий) принцип, а лишь доказывают его динамичность и гибкость, его зависимость от общих тенденций развития русской языковой системы и от специфики конкретных языковых единиц, ставших объектом нормирования. Точное соотнесение подобных крылатых слов и выражений с первоисточником, таким образом, и становится для нашего материала главным способом кодификации и минимизации отбора этих единиц. Поскольку проектируемый словарь является нормативным и рекомендующим, исходные крылатые слова и выражения описываются в нём с большей степенью регламентаций, чем в нашем «Большом словаре крылатых слов русского языка» (Berkov, Mokienko, Shulezhkova 2008), на основе которого составляется настоящий справочник. Вариантность и источниковедческие разночтения в нём должны быть сведены до минимума.

Ориентация на по возможности точно установленный первоисточник и исходную форму крылатых слов и выражений имеет и весьма полезный культурологический аспект. Ведь эти языковые единицы являются «золотой кладовой» как национально специфической, так и интернациональной общекультурной информации.

Сам источник обычно маркирует их с достаточной точностью во времени и пространстве. Вот основные группы крылатых слов и выражений, в которых отражены эти две составляющие русской культуры, в том числе и культуры языковой:

1) крылатые слова и выражения из русского (resp. славянского) фольклора, мифологии и т.п.: Делу время, потехе час; кисельные реки, молочные берега; по шучьему велению [, по моему хотению]; Хочу - казню, хочу - милую; Кощей Бессмертный; Илья Муромец и т.п.

2) крылатые слова и выражения из русской классической, советской и новейшей литературы: Живи $u$ давай жить другим (Г.Р. Державин); Лебедь, Рак и Щука (И.А. Крылов); гений чистой красоты (А.С. Пушкин); человек в футляре (А.П. Чехов); Всё в человеке, всё для человека! (М. Горький); Калина красная (В.М. Шукшин). 
3) крылатые слова и выражения из русского классического, советского и новейшего искусства (живопись, театр, кино, песенная культура, эстрада и т.п.): Последний день Помпеи (К.П. Брюллов); Не ждали (И.Е. Репин); Любви все возрасты покорны (П.И. Чайковский); Хотят ли русские войны? (Э. Колмановский); Свой среди чужих, чужой среди своих (Н.С. Михалков); Гюльчатай, открой личико! (кинофильм «Белое солнце пустыни» (реж. В.Мотыль); Миллион, миллион, миллион альхх роз (Р. Паулс); В греческом зале (М. Жванецкий, А. Райкин).

4) крылатые слова и выражения из речи русских исторических деятелей, политиков и т.п.: Иду нa $6 b l$ (князь Святослав Игоревич); Промедление смерти подобно (Петр I); Тяжело в учении - легко в бою (А.В. Суворов); Прочесс пошёл (М.С. Горбачёв); Хотели как лучше, а вышло, как всегда (В.С. Черномырдин); мочить в сортире (В.В. Путин).

5) крылатые слова и выражения из современной рекламы: сладкая парочка; правильное пиво; Не тормози - сникерснись!

6) крылатые слова и выражения из Библии (как интернациональные, так и собственно русские): ставить что во главу угла; манна небесная; великие (сильные) мира сего; умывать руки; Не хлебом единым жив человек; Святая Троица.

7) крылатые слова и выражения из европейского и мирового фольклора, мифологии и т.п.: Фурия, как Цербер, (быть, находиться) между Сциллой и Харибдой; Танталовы муки, лебединая песня.

8) крылатые слова и выражения из европейской и мировой античной, классической, и современной литературы: львиная доля (Эзоп); Надежда умирает последней (Цицерон); Много шума из ничего (В. Шекспир); дух времени (И.-В. Гёте); Праздник, который всегда с тобой (Э. Хемингуэй); На западном фронте без перемен (Э.М. Ремарк); Mы в ответе за тех, кого приручили (А. де Сент-Экзюпери).

9) крылатые слова и выражения из европейского и мирового классического и современного искусства (живопись, театр, кино, песенная культура, эстрада и т.п.): Возвращение блудного сына (Х. ван Рейн Рембрандт); дойная корова (Ж.-Б. Мольер); мистер Икс (И. Кальман); В джазе только девушки (американский фильм, реж. Б. Уайлдер).

10) крылатые слова и выражения из речи зарубежных исторических деятелей, политиков и т.п.: Благо народа - высший закон (Цицерон); Язык дан человеку для того, чтобы скрывать свои мысли (Ш.М. Талейран); холодная война (У. Черчилль); звёздные войны (Р. Рейган); бархатная револючия (В. Гавел).

Возможность в предлагаемом словаре более концентрировано представить и культурологические концепты русской речи также определяет главный акцент описания крылатых слов и выражений. Важным дидактическим параметром предлагаемого словаря станет расположение в нём крылатых слов и выражений не по сплошному алфавиту (как это обычно в названных выше словарях), а по фамилиям авторов, внёсших свой вклад в «крылатую» сокровищницу нашего языка.

Корпус предлагаемого словаря формируется на основе отбора наиболее частотных, активно употребительных крылатых слов и выражений. Однако этот критерий дополняется и критерием нормативности в указанном выше смысле, т.е. в словник включаются и такие единицы, употребительность которых не слишком велика, но источник которых носителями языка ощущается неясно, что приводит к их ошибочной идентификации и употреблению.

Использование единого определяющего критерия для отбора единиц словарного описания имеет, как известно, свои плюсы и минусы. Плюсом в нашем случае является, как кажется, сама возможность из множества реально функционирующих крылатых слов и выражений русского языка (а их не менее 10 тысяч) отобрать минимальное количество именно таких, которые чреваты неправильным указанием на источник, истолкованием и употреблением. Минусом такого отбора является определённая разнородность корпуса крылатых слов и выражений, которые необходимо описать в предлагаемом словаре. Они разнородны по следующим характеристикам: частотность функционирования в текстах разного типа, социальным и хронологическим параметрам происхождения, стилистической характеристике и тематическому диапазону. Такая разнородность вытекает из динамического характера всей современной системы крылатых слов и выражений русского языка и словник предлагаемого словаря становится поэтому её объективным отражением. Однако в словаре с минимизированным корпусом крылатых слов и выражений это их свойство требует не только оговорки, но и корректной адекватной лексикографической квалификации. Именно подобная квалификация поможет непротиворечиво решить оппозицию крылатологического «минимума и максимума».

ЗАКЛЮЧЕНИЕ . Комбинация толкования, стилистических помет и указаний на первоисточник, как кажется, создаёт, с одной стороны, относительно полную картину реального функционирования крылатых слов и выражений в современном русском языке, с другой - представляет их культурологический и коннотативный потенциал. Разумеется, полнокровному воссозданию такой картины способствовало бы и приведение контекстных иллюстраций, которыми традиционно богаты некоторые толковые словари русских крылатых слов и выражений (Ashukiny 1966, Berkov, Mokienko, Shulezhkova 2000; Chlebda, Mokienko, Szuleżkowa 2003). Oт этого параметра словарной статьи в данном случае пришлось, к сожалению, отказаться из-за заданной жанром минимизации места.

Таким образом, предлагаемый Читателю словарь ориентирован на такие параметры описания русских крылатых слов и выражений, которые позволяют обратить внимание на случаи неточного и искаженного употребления, предостерегают от потенциальных ошибок и главное - демонстрируют мощный 
культурологический потенциал метких и выразительных словечек, которые со времен Гомера быстрокрыло перелетают из уст в уста. И уже поэтому требуют к себе особого дидактического внимания.

\section{LIST OF REFERENCES}

Ashukiny Ashukin, N. S., Ashukina, M. G. (1955). Krylatye slova. Literaturnye citaty. Obraznye vyrazheniya. Moskva: Hudozhestvennaya literatura.

Ashukin, N. S., Ashukina, M. G. (1966). Krylatye slova. Literaturnye citaty. Obraznye vyrazheniya. 3-e izd. Moskva: Hudozhestvennaya literatura, 1966.

Ashukin, N. S., Ashukina, M. G. (1999). Krylatye slova. Moskva: FAIR-PRESS, 1999.

Berkov, V. P., Mokienko, V. M., Shulezhkova, S. G. Bol'shoy slovar' krylatyh slov russkogo yazyka. (2000). Moskva: «Russkie slovari», OOO «Izdatel'stvo Astrel'», OOO «Izdatel'stvo AST».

Berkov, V. P., Mokienko, V. M., Shulezhkova, S. G. Bol'shoy slovar' krylatyh slov i vyrazheniy russkogo yazyka : ok. 5000 ed. : v $2-$ h t. (2008-2009). Pod red. S. G. Shulezhkovoy. - 2-e izd., ispr. i dop. - Magnitogorsk : MaGU; Greifswald : Ernst-Moritz-ArndtUniversität.

Walter, H., Mokienko, V. M. (2005). Antiposlovicy russkogo naroda. SPb.: Izdatel'skiy Dom «Neva».

Dyadechko, L. P. (2001-2003). Novoe v russkoy i ukrainskoy rechi: Krylatye slova - krilati slova (materialy dlya slovarya). Uchebnoe posobie. Kiïv: «Komp'yuterpres».

Zaymovskiy, S. G. (1930). Krylatoe slovo. Spravochnik citaty i aforizma. Moskva-Leningrad, 1930.

Lomakina O.V., Mokienko V.M. Krylatika v sovremennom kul'turnom kontekste // Vestnik Rossiyskogo universiteta druzhby narodov. Seriya: Teoriya yazyka. Semiotika. Semantika. T. 10. № 2. S. 256-272. doi: 10.22363/2313-2299-2019-10-2-256-272. Maksimov, S. V. (1891, 1955). Krylatye slova. SPb; Moskva: GIHL, 1955.

Mihel'son, M. I. Russkaya mysl' i rech'. Svoe i chuzhoe. Opyt russkoy frazeologii. Sbornik obraznyh slov i inoskazaniy. (1903, 1905). SPb. - T. 1, 2.

Mihel'son, M. I. Russkaya mysl' i rech'. Svoe i chuzhoe. Opyt russkoy frazeologii. Sbornik obraznyh slov i inoskazaniy. Predislovie i kommentarii V. M. Mokienko. (1994). Moskva: «Russkie slovari», 1994.

Mokienko, V. M., Sidorenko, K. P. Slovar' krylatyh vyrazheniy Pushkina. (1999). SPb.: izd-vo SPbGU - Folio-Press.

Norman, B.Yu. Lingvistika kazhdogo dnya. (2004). Minsk: izd-vo «Biznes-Yunitek». Ovsyannikov, V.Z. Literaturnaya rech'. Tolkovyy slovar' sovremennoy obscheupotrebitel'noy frazeologii / Sostavil V.Z. Ovsyannikov. (1933). Moskva.

Rednikov, I. Sbornik zamechatel'nyh izrecheniy, citat, pogovorok i t.p. razlichnyh vremen i narodov s istoricheskim i sravnitel'nym ob'yasneniem. (1883). Vyatka.

Serov, V. Krylatye slova: Enciklopediya. (2003). Moskva: Lokid-Press.

Suprun, A.E. Issledovaniya po lingvistike teksta. (2001). Minsk. Shulezhkova, S. G. Krylatye vyrazheniya russkogo yazyka, ih istochniki i razvitie. (2002). Moskva: «Azbukovnik».

Baláková, Dana. Biblická frazeológia v po/vedomí slovenskej, ruskej a nemeckej mladej generálie // Die slawische Phraseologie und die Bibel - Славянская фразеология и Библия - Slovanská frazeológia a Biblia. Kollektivmonographie. - Redaktion: Harry Walter, Valerij M., Dana Balaková. (2013). Greifswald: Ernst-Moritz-Arndt-Universität Greifswald.

Chlebda, Wojciech, Mokienko, Valerij M., Szuleżkowa, Swietłana G. Rosyjsko-polski słownik skrzydlatych słów. (2003). - Łask: Oficyna Wydawnicza Leksem, 2003.

Mokienko, V. Intertexteme und Text in slavischen Sprachen // Funktionale Beschreibung slavischer Sprachen. Beiträge zum XIII. Internationalen Slavistenkongress in Ljubljana. Hrsg. Tilman Berger, Karl Gutschmidt. (2003). München: Verlag Otto Sagner, 2003. - S. 162-186.

\section{For citation:}

Mokienko, V.M. (2019) WINGED WORDS IN SCHOOL: MINIMUM AND MAXIMUM. International Scientific-Pedagogical Organization of Philologists “WEST-EAST” (ISPOP). Scientific Journal WEST-EAST. Vol 1/1 N1 (October, 2019). pp. 11-16. doi:

\section{Для цитирования:}

Мокиенко, В. М. (2019) КРЫЛАТЫЕ СЛОВА В ШКОЛЕ: МИНИМУМ И МАКСИМУМ // International Scientific-Pedagogical Organization of Philologists "WEST-EAST" (ISPOP). Scientific Journal WEST-EAST. Vol 1/1 N1 (October, 2019). C. 11-16. doi:

Information about the author: Valerij Mokienko - Doctor of Philological Sciences, Professor, Departement of the Slavic Philology, Saint-Petersburg State University, the head of the Phraseological School of the St.-Petersburg University. Professor Dr. h.c. em. Ernst-Moritz-Arndt-University Greifswald (Germany); the Honour Professor of the Olomouc University (Czech Republic) and the President of the Phraseological Commission by the International Commitee of Slavists. Chairman of the Scientific Council of International Scientific-Pedagogical Organization of Philologists "WEST-EAST" (ISPOP), Chairman of the Scientific - Editorial Council of Scientific Journal "WEST-EAST".

e-mail: mokienko40@mail.ru

Сведения об авторе: В. М. Мокиенко - Доктор филологических наук, профессор, Санкт-Петербургский государственный университет (Россия), Университет им. Эрнеста Морица Арндта (Германия), Оломоуцкий университет (Чешская республика). Презедент Международного комитета славистов. Председатель научного совета Международной научнопедагогической организации филологов «Запад - Восток», председатель научно-редакционного совета международного научного журнала "WEST-EAST".

e-mail: mokienko40@mail.ru 